\title{
Oxygen dynamics in permeable sediments with wave-driven pore water exchange
}

\author{
Elimar Precht, ${ }^{1}$ Ulrich Franke, Lubos Polerecky, and Markus Huettel ${ }^{2}$ \\ Max Planck Institute for Marine Microbiology, Celsiusstrasse 1, D-28359 Bremen, Germany
}

\begin{abstract}
The effects of advective pore water exchange driven by shallow water waves on the oxygen distribution in a permeable $\left(k=3.3 \times 10^{-12}\right.$ to $\left.4.9 \times 10^{-11} \mathrm{~m}^{2}\right)$ natural sediment were studied with a planar oxygen optode in a wave tank. Our experiments demonstrate that pore water flow driven by the interaction of sediment topography and oscillating boundary flow changes the spatial and temporal oxygen distribution in the upper sediment layer. Oxygenated water intruding in the ripple troughs and deep anoxic pore water drawn to the surface under the ripple crests create an undulating oxic-anoxic boundary within the upper sediment layer, mirroring the topographical features of the sediment bed. Anoxic upwelling zones under ripple crests can separate the oxic sediment areas of neighboring ripple troughs with steep horizontal oxygen concentration gradients. The optode showed that migrating wave ripples are trailed by their pore water flow field, alternately exposing sediment volumes to oxic and anoxic pore water, which can be a mechanism for remobilizing particulate oxidized metal precipitates and for promoting coupled nitrification-denitrification. More rapid ripple migration (experimental threshold $\sim 20 \mathrm{~cm} \mathrm{~h}^{-1}$ ) produces a continuous oxic surface layer that inhibits the release of reduced substances from the bed, which under slowly moving ripples is possible through the anoxic vertical upwelling zones. Swift, dramatic changes in oxygen concentration in the upper layers of permeable seabeds because of surface gravity waves require that sediment-dwelling organisms are tolerant to anoxia or highly mobile and enhance organic matter mineralization.
\end{abstract}

The dominant boundary layer flows in shallow marine environments are those generated by surface gravity waves. This dominance is reflected by the presence of wave ripples structuring large areas of shallow sandy seabeds that are abundant in coastal, estuarine, and shelf environments. Most of these sandy sediments are permeable $\left(k>10^{-12} \mathrm{~m}^{2}\right)$ and thus allow interstitial water motion. Pressure differences at the sediment-water interface might drive interfacial solute transport through the surface layers of these beds. This advective transport can exceed transport by molecular diffusion by several orders of magnitude (Huettel and Webster 2001). In contrast, the major transport mechanisms in fine-grained muddy sediments are molecular diffusion and locally bioturbation (Berner 1980; Aller 1982).

Increased fluid exchange between sediment and overlying water affects the oxygen dynamics in permeable sediments and therefore also affects biogeochemical processes. Booij

\footnotetext{
${ }^{1}$ Corresponding author (eprecht@mpi-bremen.de).

${ }^{2}$ Present address: Florida State University, Department of Oceanography, Tallahassee, FL 32306-4320.
}

\section{Acknowledgments}

Bo Barker Jørgensen is acknowledged for support and constant interest in this work. Hans Røy is thanked for initial discussions, helpful comments, and help during fieldwork. For assistance with the planar oxygen optodes, Gerhard Holst and Björn Grunwald are acknowledged. We thank Gabi Schüßler, Susanne Menger, and Martina Alisch for assistance with the experiments, sampling, and analyses and Volker Meyer and Georg Herz for their help with the electronics and the flume setup. Ingo Klimant (Institute for Analytical Chemistry, Micro- and Radiochemistry, Technical University of Graz, Austria) and Gregor Liebsch (Institute for Analytical Chemistry, Bio- and Chemo-Sensors, University of Regensburg, Germany) are thanked for the preparation of the planar $\mathrm{O}_{2}$ optode. We acknowledge the valuable comments of Ronnie Glud, M. M. Rutgers van der Loeff, and one anonymous reviewer. The study was funded by the Max Planck Society (MPG). et al. (1991) showed in benthic chamber experiments that oxygen-rich water can be advected vertically into sandy sediment, which increased the oxygen penetration depth in the sediment as a function of the flow velocity of the overlying water. Advective oxygen distribution in permeable sand because of unidirectional boundary flow interacting with sediment topography was studied by Ziebis et al. (1996), who showed that oxygen is transported rapidly and effectively into deeper sediment layers and could thus enhance mineralization of organic matter (Forster et al. 1996). This organic matter could be transferred from the boundary layer into the top centimeters of the sediments as suspended particles or phytoplankton by advection (Huettel et al. 1996b; Huettel and Rusch 2000). As a consequence of these processes, advective pore water flow can generate a complex biogeochemical zonation in the sediment with areas of enhanced nitrification or iron precipitation and vertical channels through which ammonium and reduced metals are transported to the sediment surface (Huettel et al. 1998).

Surface gravity waves produce oscillating flows at the sediment-water interface by the wave orbital water motion (e.g., see p. 54 in Denny 1988) in areas with a water depth shallower than half the wavelength of the waves. The ability of such oscillating boundary flows to drive pore water flow was shown by Webb and Theodor $(1968,1972)$ by injecting dyed water into coarse, sandy, nearshore sediment and observing its reappearance at the sediment surface. Wave-driven in situ pore water velocities were measured by Precht and Huettel (2004). Shum (1992) calculated the pore water motion under a rippled bed over one wave period with a twodimensional computational model, showing that the zone of advection extends several ripple heights below the ripple surface over a wide range of wave conditions and sediment characteristics. These transport studies suggest that waves, by enhancing advective fluid exchange between sediment and overlying water, also affect the biogeochemical process- 
es in permeable beds in the same way as unidirectional flows. Oxygen distributions underneath a rippled surface exposed to progressing waves modeled by Shum (1993) revealed that, in permeable beds, oxygen concentration gradients in the horizontal might be the same order of magnitude as those in the vertical. In a wave tank study quantifying the wave-induced advective interfacial exchange, Precht and Huettel (2003) showed that horizontal tracer concentration gradients migrate with sediment topography (ripple) propagation. These authors suggested that this could be of significance for sediment oxygen dynamics because sediments might alternately be exposed to changing oxygen concentrations.

The planar oxygen optode technique employed in this study to assess the oxygen dynamics in the sediment was introduced by Glud et al. (1996) and has been used successfully to measure oxygen production, consumption, and dynamics in marine systems (e.g., microbial mats, Glud et al. 1998, 1999). Glud et al. (2001) also developed an in situ instrument for planar $\mathrm{O}_{2}$ optode measurements at benthic interfaces.

The aim of this study was to elucidate the effects of advection driven by wave-generated oscillating boundary flow interacting with mobile sediment topography on the oxygen dynamics of natural sediment. To achieve this goal, experiments were carried out in natural sandy sediment in a laboratory wave tank with a planar oxygen optode.

\section{Materials and methods}

Sediment and sediment preparation-The sediment used in this study was collected in an intertidal flat at Sylt Island in the German North Sea $\left(55^{\circ} 2^{\prime} \mathrm{N}, 08^{\circ} 26^{\prime} \mathrm{E}\right)$ in February 2001 at a temperature of $4^{\circ} \mathrm{C}$. Sediment was sampled in two layers: the top $2 \mathrm{~cm}$, then down to $20 \mathrm{~cm}$ depth. These sediments were transported separately and were combined again in the laboratory wave tank within $24 \mathrm{~h}$ of sampling. The wave tank was filled with $\sim 1,750$ liters of artificial seawater (Instant Sea ${ }^{\text {(ix) }}$ ) with a salinity of 31 and kept at a constant temperature of $17^{\circ} \mathrm{C}$.

The sediment surface was leveled by the foraging activity of a small Carcinus maenas crab, which also eliminated the initially abundant Hydrobia ulvae mud snails. The sediment then was left under a constant recirculating unidirectional flow of $\sim 5 \mathrm{~cm} \mathrm{~s}^{-1}$ (at $10 \mathrm{~cm}$ above the bed) for 12 months to regain a quasi-natural balance. Infauna consisted mostly of oligochaetes of the Tubificidae family living in the upper $2 \mathrm{~cm}$ of the sediment. No nourishment was added to the wave tank during the first months after the setup to prevent accumulation of nutrients. Starting 8 weeks before and during the experiments, powdered dried red algae (ground to a particle size between 125 and $250 \mu \mathrm{m}$ ) equivalent to an input of $1 \mathrm{~g} \mathrm{~m}^{-2}$ was added biweekly by suspending the material and evenly distributing it in the wave tank.

Sediment analyses-At the sediment sampling site, sediment cores $(2.6 \mathrm{~cm}$ diameter, $12 \mathrm{~cm}$ long) were taken for measurement of in situ permeability and porosity. Three representative sediment samples were additionally taken for grain size analyses. Before and after the experiments, sedi- ment cores $(2.6 \mathrm{~cm}$ diameter) were taken in the wave tank for analyses of permeability $(\sim 12 \mathrm{~cm}$ long), porosity $(10 \mathrm{~cm}$ long), and grain size distribution $(10 \mathrm{~cm})$. Additionally, grain sizes and permeability of the upper $2.5 \mathrm{~cm}$ of the sediment were assessed.

For porosity and pore water analysis, the sediment subcores taken in-situ and from the laboratory wave tank were sectioned into 1-cm-thick horizontal slices. Porosity averaged over depth, as calculated from wet and dry (after drying until constant weight at $60^{\circ} \mathrm{C}$ ) weights of the sediment slices, was $37.1 \%(\mathrm{SD}=2.0, n=10)$ in situ, $34.0 \%(\mathrm{SD}=2.3$, $n=20$ ) before the experiments, and $36.2 \%$ (SD $=3.8, n=$ 30) after the experiments. The sediment subcores used to assess the permeability were sealed after sampling and stored at $4^{\circ} \mathrm{C}$ until the measurements were carried out within a few days. Permeability was assessed by the constant head method (Klute and Dirksen 1986) directly on the retrieved sediment cores. Values for density and dynamic viscosity were calculated after Krögel (1997). In situ sediment permeability was $7.6 \times 10^{-12} \mathrm{~m}^{2}\left(\mathrm{SD}=1.4 \times 10^{-12} \mathrm{~m}^{2}, n=4\right)$ and wave tank permeability $3.3 \times 10^{-12} \mathrm{~m}^{2}\left(\mathrm{SD}=0.8 \times 10^{-12}\right.$ $\mathrm{m}^{2}, n=2$ ), with higher permeability of the surface sediment (upper $2.5 \mathrm{~cm})$ of $4.9 \times 10^{-11} \mathrm{~m}^{2}\left(\mathrm{SD}=0.04 \times 10^{-11} \mathrm{~m}^{2}\right.$, $n=3$ ). In situ grain size distribution was determined by desalination, drying, and sieving with a set of eight calibrated sieves. The median grain size of the sediment was $180 \mu \mathrm{m}$.

Wave tank setup-The laboratory wave tank used in this study was made of clear acrylic and had an open channel length of $520 \mathrm{~cm}$ with a rectangular cross section $(50 \mathrm{~cm}$ high, $47 \mathrm{~cm}$ wide). Two acrylic boxes were put into the open channel section (upstream box: $240 \mathrm{~cm}$ long, downstream box: $120 \mathrm{~cm}$ long, both $19 \mathrm{~cm}$ high and spanning the entire width of the channel) such that the gap between the two boxes had a width of $120 \mathrm{~cm}$ and could be filled with sediment (Fig. 1). Filled with a sediment layer of $22 \mathrm{~cm}$ depth, this setup amounted to a sediment volume of $124 \mathrm{dm}^{3}$. The two boxes in the open channel section were covered with 3 $\mathrm{cm}$ of sediment to create an overall even surface with uniform roughness throughout the open channel section. Initially, the sediment surface was level, and all subsequent ripple formation was the response of the bed to the applied wave action. Waves were generated at the upstream end of the wave tank with a paddle driven by an electric motor, controlling wave amplitude by the stroke of the eccentric and wave frequency via motor speed. This setup permitted reproducible generation of sinusoidal waves of selected amplitude and frequency. At the downstream end of the wave tank, the dissipation of the waves was achieved by an artificial beach made of an acrylic plate $1 \mathrm{~m}$ long covered by a 10 -cm-thick mat of highly permeable plastic foam, causing the waves to run up and break.

Hydrodynamics - The hydrodynamic conditions in the wave tank were measured with a three-beam DANTEC LDA (laser doppler anemometer) system in the backscatter mode. This LDA technique allows three-dimensional measurements of the flow velocity in a spheroidal measuring volume $600 \mu \mathrm{m}$ long and $70 \mu \mathrm{m}$ in diameter. During the 


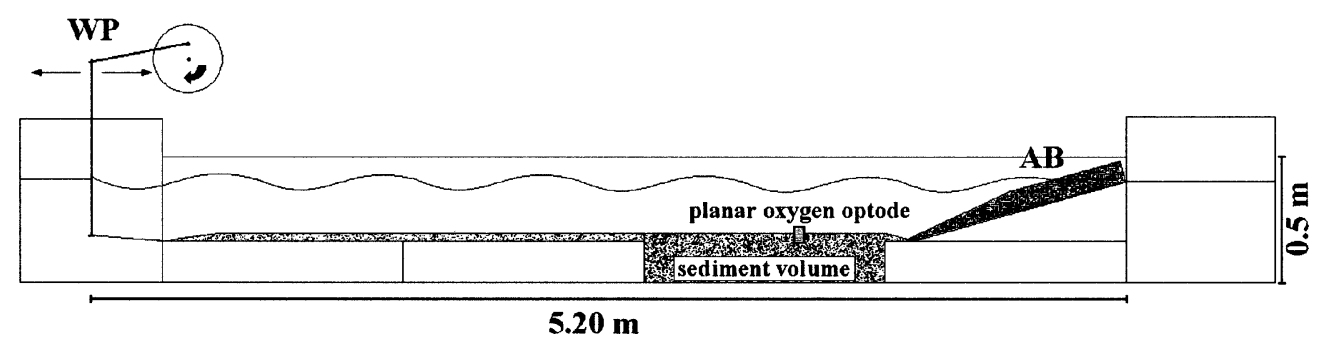

Fig. 1. Wave tank setup. WP, wave paddle; AB, artificial beach.

experiments, vertical velocity profiles $(120-0.5 \mathrm{~mm}$ above the sediment) of the horizontal and vertical velocities were measured above unrippled sections of the experimental sediment surface. In the water layer closer than $6 \mathrm{~mm}$ to the sediment-water interface, the LDA setup only allowed the measurement of the horizontal velocity component. During the experiments in which ripples formed, the root mean square values of the horizontal velocity $\left(U_{\mathrm{RMS}}\right) 12 \mathrm{~cm}$ above the sediment surface ranged from 0.12 to $0.14 \mathrm{~m} \mathrm{~s}^{-1}$. In the experiments with flow not sufficient to initiate sediment mobilization, $U_{\mathrm{RMS}}$ was $\sim 0.06 \mathrm{~m} \mathrm{~s}^{-1}$.

Oxygen measurements - The two-dimensional oxygen distribution was measured with a planar semitransparent oxygen optode ( $3.7 \mathrm{~cm}$ wide, $5.7 \mathrm{~cm}$ high) glued to the inside wall of the wave tank such that $2.7 \mathrm{~cm}$ of the optode was above and $3 \mathrm{~cm}$ was below the level sediment-water interface. The optical oxygen measurement is based on the dynamic or collisional quenching of the luminescence of an indicator by oxygen (Kautsky 1939). Commonly used oxygen indicators are platinum-porphyrins embedded in a polystyrene matrix (Papkovsky et al. 1992; Liebsch et al. 2000).

The planar sensing foils comprised two layers: a transparent polyester support foil (125 $\mu \mathrm{m}$ thick, Goodfellow) and the sensing layer, which was spread by knife. The luminescent oxygen indicator $(59 \mathrm{mg}$ ) platinum(II) mesotetra (pentafluorophenyl) porphyrin (Pt-PFP, Porphyrin Products) was dissolved in $14.7 \mathrm{~g}$ chloroform (Merck, Darmstadt) and $1.63 \mathrm{~g}$ polystyrene (Sigma-Aldrich). To increase the amount of excitation light within the sensing layer, $1.63 \mathrm{~g}$ titanium dioxide particles $\left(\mathrm{TiO}_{2}<5 \mu \mathrm{m}\right.$, Aldrich) were added. These particles do not interfere with the quenching but enhance the signal by scattering. Therefore, they increase the output luminescence signal at the expense of loosing a clear view of the structure behind the sensor (Klimant and Wolfbeis 1995). The concentration of the fluorophore in the cured sensing layer was $1.8 \%(\mathrm{w} / \mathrm{w})$. The thickness of the semitransparent sensing layer was approximately $30 \mu \mathrm{m}$, resulting in an overall thickness of the planar optode of $155 \mu \mathrm{m}$.

The $\mathrm{O}_{2}$ distribution measurements were conducted by the specially developed modular luminescence lifetime imaging system, MOLLI, as described by Holst et al. (1998) and Holst and Grunwald (2001). The planar optode was illuminated by blue $\left(\lambda_{\max }=475 \mathrm{~nm}\right)$ excitation light of diodes (LEDs, HLMP-CB 15, Agilent), and the luminescence ( $\lambda_{\max }$ $=647 \mathrm{~nm}$ ) emitted by the optode was filtered with a red optical filter ( $80 \%$ transmission at $\geq 620 \mathrm{~nm}$; Deep Golden Amber, LEE-Filters) to remove most of the reflected exci- tation light. The luminescence images of the planar optode were recorded by a charge-coupled device (CCD) camera (SensiCam, PCO) with a resolution of $640 \times 480$ pixels. The images covered an area of $25.6 \times 19.2 \mathrm{~mm}$. Taking the thickness of the sensing layer $(30 \mu \mathrm{m})$ and the spatial resolution of the imaging system into account, the spatial resolution of the oxygen images was $40 \times 40 \mu \mathrm{m} \mathrm{pixel}{ }^{-1}$. In order to determine the distribution of oxygen concentrations, the two-dimensional luminescence lifetime distributions were evaluated by the rapid lifetime determination (RLD) method (Woods et al. 1984; Ballew and Demas 1989; Liebsch et al. 2000). Further image processing was carried out with a custom-made computer program (Holst and Grunwald 2001). The planar optode was calibrated before and after the experiments by recording images corresponding to $0 \%$ and $100 \%$ air saturation. The measured luminescence lifetime distributions were converted into oxygen concentration values by a modified two-component model of the Stern-Volmer equation (Klimant et al. 1995; Holst and Grunwald 2001).

The accuracy of the oxygen measurements of the optode, as determined with 11 high-frequency measurements, was $\pm 7 \%$ of air saturation at $70-90 \%$ air saturation and $\pm 2.5 \%$ at $0-10 \%$ air saturation. The lower accuracy at higher oxygen concentrations occurs because higher oxygen content leads to a weaker luminescence signal. The stability of the optode was checked by calibrations before and after the experiments, and the calibration function of the sensor foil did not change significantly during $1.5 \mathrm{yr}$ of experiments. The rate at which the optode could accurately follow changes is $\sim 1 \mathrm{~Hz}$, which is significantly lower than the measuring intervals employed (minutes).

Sediment topography-The sediment relief in front of the planar optode had to be assessed simultaneously with the oxygen measurements. This was achieved by a CCD camera positioned on the side of the wave tank opposite the planar optode. The camera's field of vision covered the area of the planar optode and was fixed slightly elevated relative to the optode in a $10^{\circ}$ downward angle so that the sediment topography directly in front of the optode did not obstruct vision (Fig. 2). The camera was triggered simultaneously with the diodes that emitted the excitation light for the oxygen measurements. Thus, the obtained images showed the planar optode with the background light of the diodes and was partly darkened by the respective sediment relief. The sediment relief was assessed from these images with an edge-detecting algorithm that used the transition between dark and light 


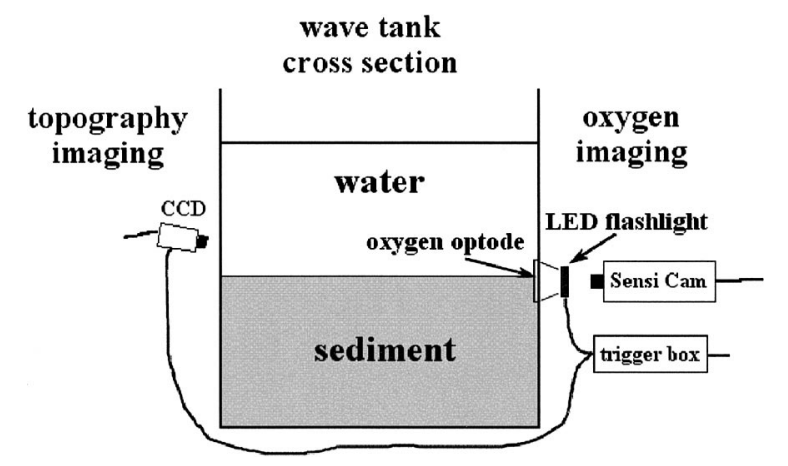

Fig. 2. Side view of the setup for the simultaneous oxygen and surface topography imaging in the wave tank.

regions of the image corresponding to the sediment surface relief. With three fluorescently marked reference points, the horizontally mirrored image of the sediment surface relief and oxygen distribution images could be aligned precisely. The sediment relief line was superimposed on the oxygen distribution images in a batch conversion routine. Time sequences of the resulting composite images were combined to produce animations of the oxygen dynamics in the sediment, simultaneously showing the changes of the sediment relief.

Experiments-To assess pore water velocities and pore water flow patterns under typical wave conditions, an experiment was carried out with waves equivalent to those in experiments 2, 5, 6, and 7 (Table 1). Prior to the experiment, the sediment surface was leveled. After the waves were switched on, ripples formed (wavelength $=2.5 \mathrm{~cm}$, amplitude $=0.5 \mathrm{~cm}$ ), and Rhodamine WT solution was injected into the sediment at various locations adjacent to the transparent wave tank wall next to the planar optode-ripple troughs and crests included. The development of the dye clouds in the sediment was recorded in high-resolution photographs taken at distinct time intervals (15 or $60 \mathrm{~s}$ ). From the dye migration, the pore water velocities could be assessed.

Seven successful wave tank oxygen dynamics experiments were conducted between April and June 2002. All experiments were carried out with surface gravity waves of variable lengths and heights. The bed was smoothed before the experimental runs, and no artificial roughness elements were placed on the sediment surface. Exceptions were experiments 3 and 4, which were carried out with the remaining sediment topography of the previous experiment 2 to test the case of identical sediment topography and decreased flow velocities. During all experiments, oxygen images measured by the planar optode, together with the sediment relief images, were recorded. The experimental parameters relevant to the different experimental settings are listed in Table 1.

\section{Results}

Ripples-Orbital wave ripples formed in all experiments with smooth sediment surfaces in a matter of minutes (Table 1). However, the ripple evolution did not occur in a regular

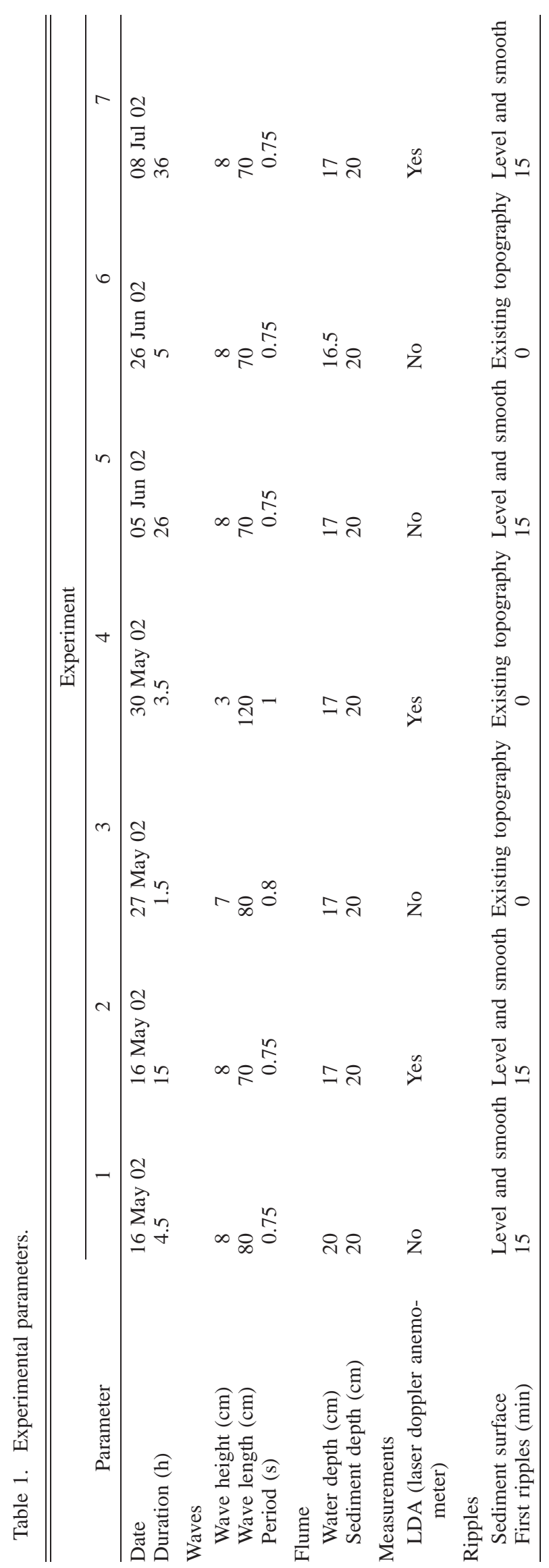




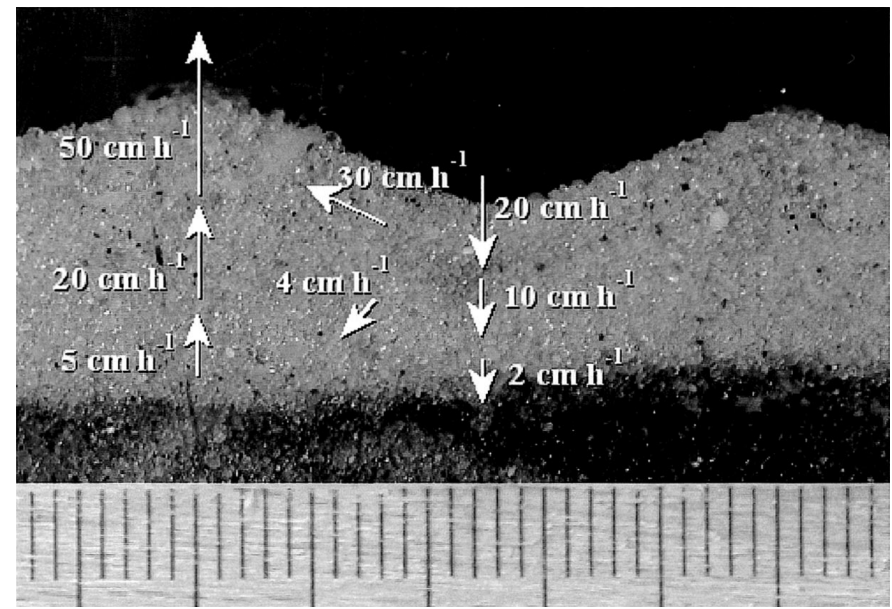

Fig. 3. Summary of pore water velocity measurements conducted with soluble tracer. The arrows indicate the observed pore water directions and are not to scale. The scale bar $(\mathrm{mm})$ is shown at the bottom.

manner and uniformly in all experiments. Usually, ripples evolved in patches and spread over the rest of the sediment surface. Therefore, it could take some time until ripples formed in front of the planar optode. Ripple migration did not occur continuously and was characterized by variable velocities. Moreover, it could be observed that in the first experiment, ripple evolution was generally slower, which can most likely be attributed to EPS (extracellular polymeric substances) excreted by active organisms on the sediment surface. This effect was however not investigated further in the experiments.

Pore water velocity - A symmetrical advective flow pattern develops when the oscillating boundary flows interact with the wave ripples. Water enters the sediment at the ripple troughs and leaves it at the ripple crests. Figure 3 shows the directions of pore water movement with the corresponding velocities assessed from the measurements of the injected dye clouds. Pore water velocities are higher closer to the sediment and lie in the range of centimeters to decimeters per hour.

Oxygen measurements - The average oxygen penetration depth into the sediment under stagnant conditions without waves was $\sim 3 \mathrm{~mm}$. This oxygen distribution, governed predominantly by molecular diffusion, was only locally altered by oligochaete bioirrigation (Fig. 4a).

After the waves were switched on, but prior to the formation of sediment ripples in front of the planar optode, the oxygen penetration depth slowly increased to $5 \mathrm{~mm}$ within $\sim 80$ min (Fig. 4b). This effect can be attributed to advection associated with small-scale surface roughness or wave pumping (Riedl et al. 1972).

Figure $4 a, b$ shows nonsaturation oxygen values in the water column. This is an effect that occurs when large anoxic areas are imaged by the oxygen optode. Because of reflections of the luminescent light within the acrylic wave tank wall, anoxic regions of the studied area affect the measure-
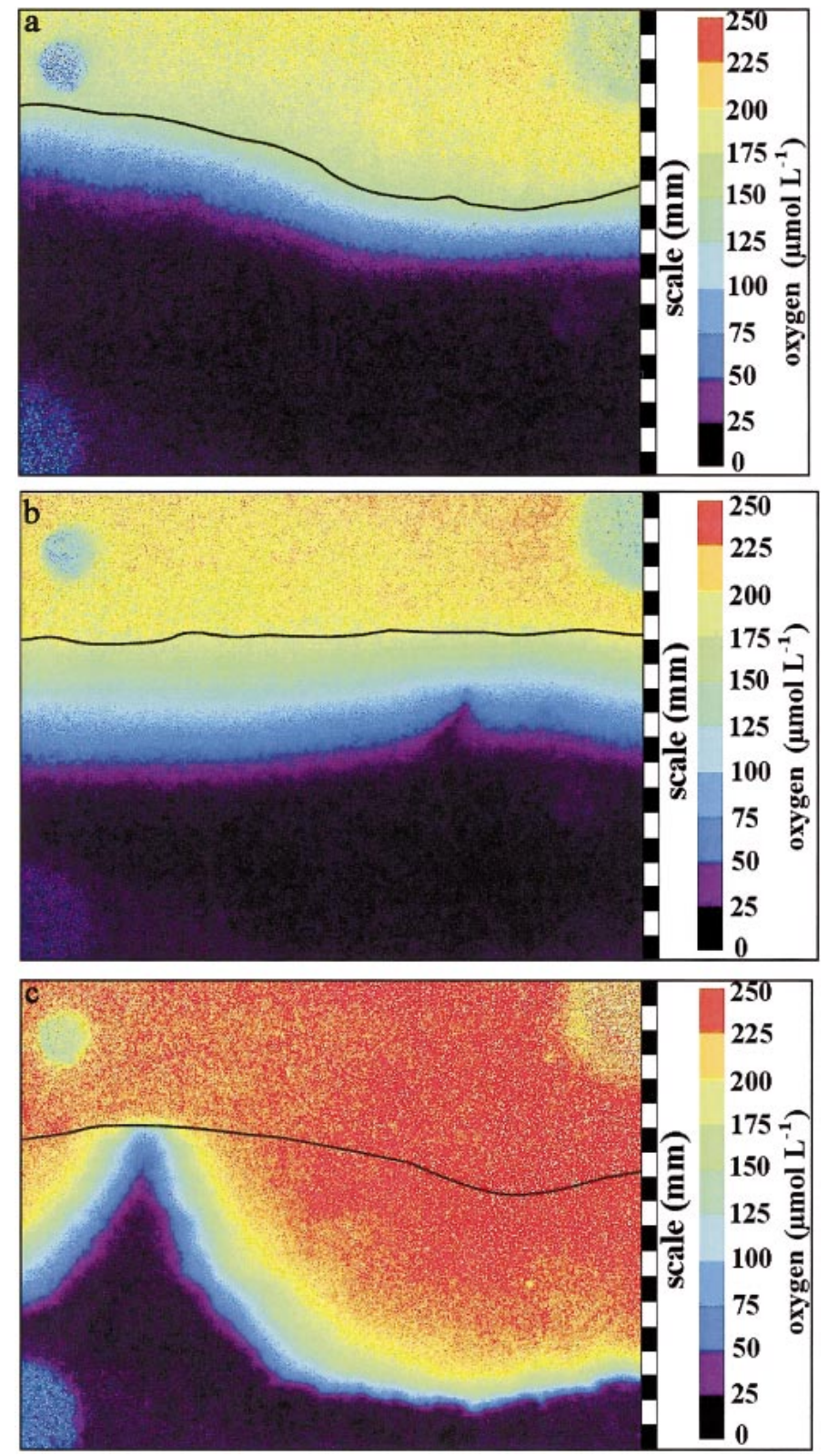

Fig. 4. (a) Oxygen image under stagnant conditions without waves (experiment 3 ). The black line indicates the sediment surface relief. (b) Oxygen image demonstrating an increased oxygen penetration depth under oscillating flow in the absence of sediment topography (experiment 6). The black line indicates the sediment surface relief. (c) Image of oxygen distribution linked to a stationary sediment ripple under oscillating flow (experiment 1). The black line indicates the sediment surface relief. Each black and white bar of the scale corresponds to $1 \mathrm{~mm}$.

ments in neighboring oxic regions. Although a reverse influence also takes place, the former is more pronounced because of the stronger luminescence intensity generated within anoxic regions. This effect lowers the spatial resolution of the oxygen images, but on a lower spatial scale than required to observe the principles of the processes studied here.

After ripples formed in front of the planar optode, the 

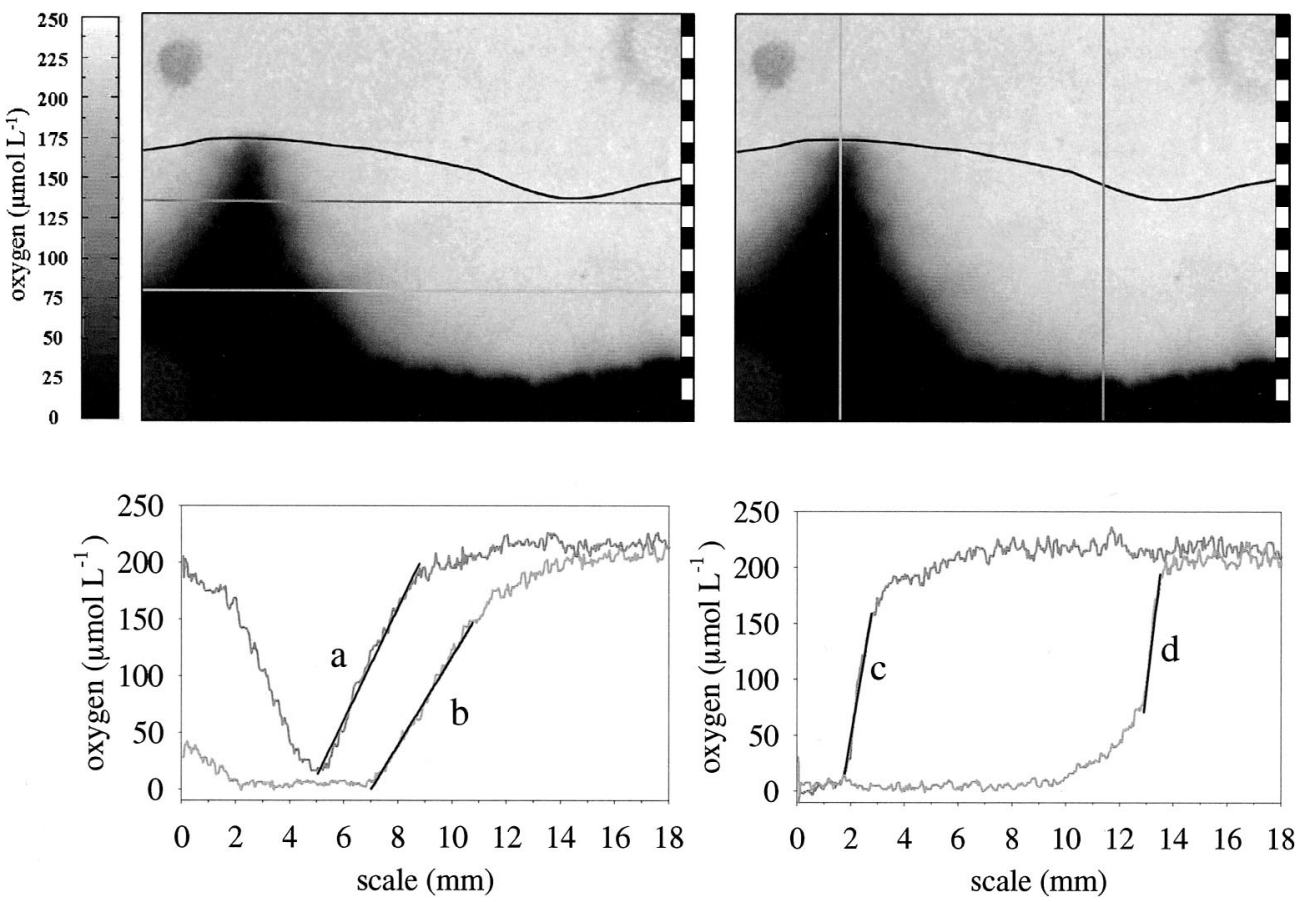

Fig. 5. Horizontal (left) and vertical (right) oxygen concentration profiles extracted from an optode image underneath a stationary ripple under oscillating flow (experiment 1). The black lines indicate the sediment surface relief; the grey lines show the extracted profiles. The depicted gradients of the oxygen concentration profiles correspond to (a) 49, (b) 39 , (c) 150 , and (d) $190 \mu \mathrm{mol} \mathrm{L}-1$ $\mathrm{mm}^{-1}$.

changes in the oxygen distribution in the sediment as a result of the ensuing advective pore water flows could be recorded with the optode. Upwelling of anoxic pore water from lower sediment layers led to an oxygen-depleted zone underneath the ripple crests. In the ripple troughs, oxygen-rich water from the water column was forced into the sediment, generating oxygenated zones in the sediment that reached a maximum depth of $1 \mathrm{~cm}$ (wave amplitude $=8 \mathrm{~cm}$, wavelength $=80 \mathrm{~cm}$; ripple amplitude $=0.4 \mathrm{~cm}$, ripple wavelength $=2.9 \mathrm{~cm}$ ). Thus, the pore water flows produced an oxygen distribution pattern reflecting the structure of the ripple topography, with alternating oxic and anoxic zones associated with ripple troughs and crests, respectively (Fig. $4 c)$. This oxygen distribution led to steep horizontal oxygen concentration gradients underneath the ripple crests (Fig. 5).

In the experiments with existing sediment ripples at the optode and flow that was not strong enough to initiate further sediment movement, it could be observed that the final oxygen distributions in the sediment were similar regardless of the hydrodynamic forcing. With decreasing wave energy, the time needed to reach the final equilibrium was increased (from $46 \mathrm{~min}$ in experiment 3 to $216 \mathrm{~min}$ in experiment 4), showing that the pore water flow pattern is dependent on the sediment topography, whereas the pore water velocity is dependent on the magnitude of the hydrodynamic forcing. With even lower bottom flows, higher oxygen consumption, or both in the sediment, one can expect the equilibrium oxicanoxic boundary to be shifted upward in the sediment because the reduced input of oxygen-rich water into the sedi- ment cannot cover the demand of oxygen-consuming processes in the sediment.

In the case of sediment ripples migrating in front of the planar optode, the pore water flow field and the associated oxygen distribution migrated with the ripples, alternately exposing sediment to oxic and anoxic conditions. This is shown in Fig. 6a (upper panel) presenting a series of oxygen distribution patterns under slowly migrating ripples.

The effect of exposing sediment alternately to variable oxygen concentrations is depicted in Fig. 6b, showing oxygen profiles extracted from the same vertical row of pixels of the two-dimensional oxygen images as a function of time. This figure demonstrates how an initial equilibrium phase (75 $\mathrm{min}$ ) was succeeded by a phase with ripple migration, causing pronounced oxygen changes in the sediment. The redox conditions at one single vertical profile in this case changed six times from anoxic to oxic within $90 \mathrm{~min}$.

When ripples migrated faster, at rates of 10 to $20 \mathrm{~cm} \mathrm{~h}^{-1}$, the oxygen-depleted zones started to lag behind the ripple crests and showed incompletely anoxic conditions (Fig. 6a, middle panel). When the ripple migration velocity in our experiments exceeded $\sim 20 \mathrm{~cm} \mathrm{~h}^{-1}$, the anoxic or oxygendepleted zone underneath the ripple crest became completely detached from the ripple topography, leading to a thick, uninterrupted oxygenated sediment surface layer (Fig. 6a, lower panel). This is in accordance with Elliott and Brooks $(1997 a, b)$, who found that release and trapping of pore water exchanges more water between the sediment and overlying 
water than advective pore water flow when the ripple migration velocity exceeds the pore water flow velocity.

The dynamics of the oxygen distribution become clearer in the animations that can be found in Web Appendix 1 (http://www.aslo.org/lo/toc/vol_49/issue_3/0693a1.html). The oxygen distribution in the sediment beneath a stationary ripple after the waves were switched on (corresponding to Fig. $4 \mathrm{a}, \mathrm{c})$, as well as the oxygen dynamics in the sediment with slowly and fast-migrating ripples (corresponding to Fig. 6), are shown.

After the waves were switched off, the effects of the sediment's oxygen consumption could be observed with the optode. The oxic-anoxic boundary slowly moved upward until oxygen distributions reached the pre-experimental state with a homogeneous diffusive oxygen penetration depth of about $3 \mathrm{~mm}$.

The oxygen consumption rates (OCRs) were calculated by fitting the changes in $\mathrm{O}_{2}$ concentration over time (Fig. 7). In a pixel close to the sediment surface (circle), the $\mathrm{O}_{2}$ concentration changed linearly with time, indicating that the effect of diffusion was negligible. The corresponding OCR, equivalent to the negative value of the slope of the $\mathrm{O}_{2}$ decrease, was $0.32 \pm 0.01 \mu \mathrm{mol} \mathrm{L}-1 \min ^{-1}$.

The situation is different in a pixel close to the oxicanoxic boundary (square). The decrease of $\mathrm{O}_{2}$ with time is initially faster $\left(\sim 1.53 \pm 0.07 \mu \mathrm{mol} \mathrm{L}{ }^{-1} \mathrm{~min}^{-1}\right.$ during the interval between 0 and $50 \mathrm{~min}$ ) and gradually slows down $\left(\sim 0.28 \pm 0.03 \mu \mathrm{mol} \mathrm{L}^{-1} \mathrm{~min}^{-1}\right.$ during the interval between 150 and $200 \mathrm{~min}$ ) because of the combined effects of oxygen consumption by the sediment and molecular diffusion that causes depletion of $\mathrm{O}_{2}$. The influence of diffusion was determined by examining the images of $\mathrm{O}_{2}$ distribution at the time intervals $0-50 \mathrm{~min}$ and $150-200 \mathrm{~min}$. It was found that the rate of the observed $\mathrm{O}_{2}$ depletion was enhanced by molecular diffusion during the first time interval, whereas it was slowed down by diffusion during the second time interval. Subtracting the contribution of molecular diffusion from the observed $\mathrm{O}_{2}$ depletion rate, we found that the true OCR here was about $0.67 \pm 0.07 \mu \mathrm{mol} \mathrm{L}-1 \mathrm{~min}^{-1}$.

Because these two pixels are representatives of two extremes, we can conclude that the $\mathrm{O}_{2}$ consumption rate varied across the oxic part of the sediment between $0.32 \pm 0.01$ and $0.67 \pm 0.07 \mu \mathrm{mol} \mathrm{L} \mathrm{L}^{-1} \mathrm{~min}^{-1}$. It should be noted that these values are expressed in terms of the volume of the pore water. If one wants to obtain the values expressed per volume of sediment, one would have to multiply them by porosity, which in our case was $\sim 36 \%$.

\section{Discussion}

We showed in a previous study (Precht and Huettel 2003) that the interaction of wave-generated oscillating boundary flows and ripple topography produced zones of up- and downwelling pore water in permeable sands that propagated with ripple migration. These finding suggested that waves can produce a complex and dynamic oxygen distribution in sandy sea beds that would strongly influence benthic organisms and sediment biogeochemistry.

Here, we demonstrated that wave-driven advective pore water flow associated with sediment wave ripples creates a pattern of sediment zones where oxygen-rich water is forced into the bed alternating with zones where anoxic pore water is drawn to the surface. The spatial and temporal distribution of these zones is closely related to the ripple topography and its changes. Because the oxygen distribution under such a rippled surface changes mainly in two dimensions, the planar oxygen optode technique proved to be a powerful tool to investigate the two-dimensional distribution and dynamics of oxygen distribution at the spatial and temporal scales of the pore water flow field.

Sediment permeability, magnitude of boundary currents, and ripple height and spacing control the advective pore water velocities, flow directions, and penetration depths (Huettel and Webster 2001). The advective penetration of a reactant like oxygen additionally depends on the consumption rates in the flushed sediment layers. Thus, the oxygen distribution pattern we observed is a complex result of oxygen injection into specific areas, with ensuing directed oxygen transport along streamlines, and sedimentary oxygen consumption characterized by a vertical gradient, with higher rates in the deeper layers. The waves transformed the smooth sediment with a thin, continuous, oxygenated surface layer into a rippled bed with a thick oxygenated layer interrupted by oxygen-depleted zones of upwelling deep pore water. Consequently, steep horizontal oxygen concentration gradients developed in the sediment, as had been predicted by Shum (1993).

The advective oxygen transport in our sediments from the wave-topography interaction was more than one order of magnitude faster than transport by diffusion (with our settings, $0.13 \mathrm{~cm}$ in $1 \mathrm{~h}$ ), explaining the relatively deep oxygen penetration into a sediment with oxygen consumption rates of $0.33-0.67 \mu \mathrm{mol} \mathrm{L}{ }^{-1} \mathrm{~min}^{-1}$. In permeable sediments with a homogeneous permeability, the vertical extension of the pore water flow field equals approximately the ripple wavelengths (Rutherford et al. 1995). The maximum oxygen penetration depth we could observe in the ripple troughs was $14 \mathrm{~mm}$, which corresponds to $18 \mathrm{~mm}$ below the flat sediment surface. With ripple wavelengths between 25 and $30 \mathrm{~mm}$, the oxygen penetration depth we observed was only slightly lower than the sediment depth theoretically affected by advection, demonstrating the dominance of oxygen injection over oxygen consumption, although our sediment had consumption rates common in shelf sediments. Because of this dominance, pore water flushing caused by the interaction of oscillating boundary flows and ripple topography increased the oxic sediment volume more than threefold in our experiments compared with the situation of a stagnant water column and diffusive transport alone.

Biogeochemical zonation-In our previous wave tank experiments (Precht and Huettel 2003), sharp boundaries of the dye patterns developed, which revealed that the pore water drawn to the surface under the ripple crest mixes very little with pore water of adjacent sediment zones. The fluid basically flows to the surface along streamlines that do not cross, except for the mixing caused by dispersion in the porous medium. Because the pore water ascends from different biogeochemical reaction zones, a pattern develops with up- 
a

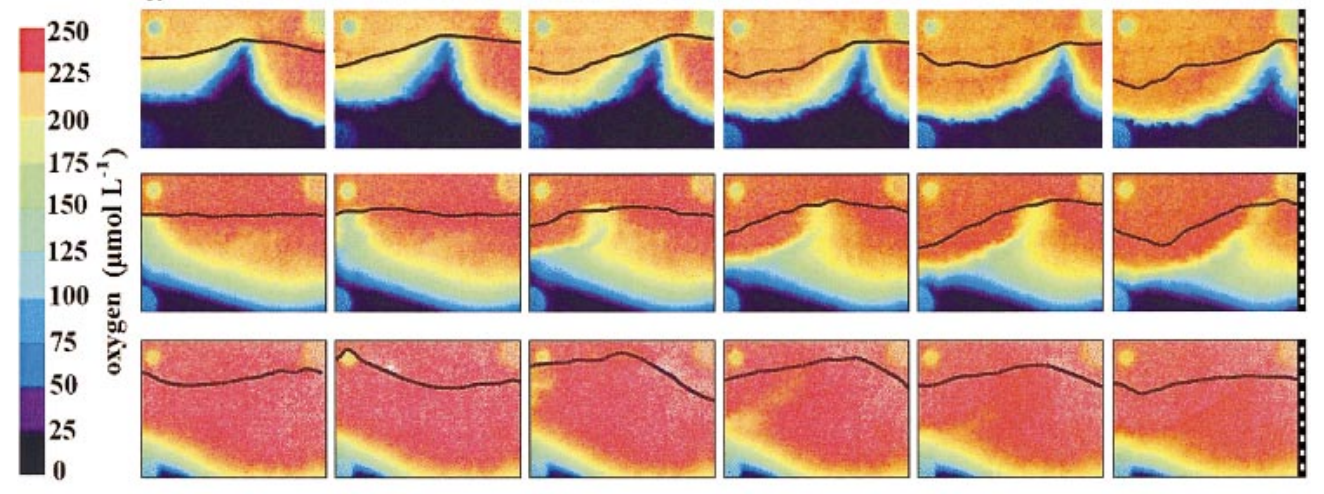

$\mathrm{b}$

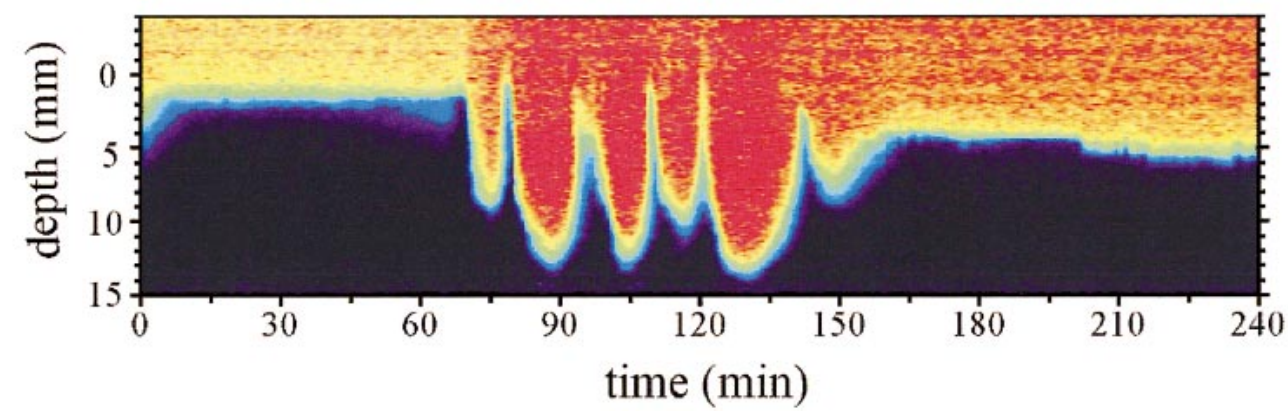

Fig. 6. (a) Time series of images of oxygen distributions under a slowly migrating ripple with a fully developed mobile upwelling zone (upper panel: image interval, 1 min; experiment 6), under a migrating ripple with an upwelling zone lagging behind the ripple crest (middle panel: image interval, 2 min; experiment 2), and under a fast-migrating ripple with no anoxic upwelling zone linked to ripple crests (lower panel: image interval, 2 min; experiment 2). (b) An example of a time series oxygen profile extracted from one selected vertical row of pixels of the planar optode images, revealing a temporal exposure of the sediment to redox oscillations (experiment 6).

welling flows that differ in their solute inventories. These pore water flows focus and narrow as they approach the ripple crest where fluid of different composition (and residence time in the sediment) emerges through narrow bands paralleling the crests (Fig. 8). With increasing distance from the center zone, these "emergence bands" release pore water from lesser and lesser depths and with shorter residence times in the sediment. As revealed by the oxygen concentration pattern under the stationary ripple (Fig. 4c), this produces bands of distinctly different geochemical characteristics at the sediment surface, which can be reflected, for example, by bands of different iron precipitates (Huettel et al. 1998). Microorganisms like sulfide oxidizers, denitrifiers, or iron oxidizers can profit from such patterns and the steep concentration gradients they produce (Fig. 5). Although the central upwelling zone might carry refractory dissolved organic matter (DOM), $\mathrm{Fe}^{2+}$, and $\mathrm{NH}_{4}^{+}$to the surface, "outer" zones might release more labile $\mathrm{DOM}$ and $\mathrm{NO}_{3}^{-}$resulting from enhanced organic matter decomposition and nitrification in the ripple slopes.

The situation in the ripple troughs is different. No solutes can be released from this area because molecular diffusion cannot counteract the water flow into the sediment. This implies that flux out of rippled permeable sediments averaged over larger areas only occurs through a fraction of the actual sediment surface area that is confined to the ripple crests. In our experiments, the total width of the upwelling zone at the ripple crest was between 6 and $8 \mathrm{~mm}$, while the sediment band separating these zones was $\sim 20-24 \mathrm{~mm}$ wide. This resulted in an uptake: release area ratio of about 3 , whereas the volume flow through both areas is the same for reasons of mass balance (which explains why the upwelling pore water flow reaches higher velocities than the downwelling flows; Fig. 3). Because the width of the upwelling zone linked to each ripple should be proportional to the ripple wavelength, we conservatively estimate that, also in natural environments, the flux from a permeable sediment into the water column occurs only in $<30 \%$ of the actual sediment surface areas in seabeds where advective exchange is effective. This demonstrates a major difference between sandy and cohesive sediment beds: in permeable seabeds, the fluxes are tightly linked to surface topography, and the fluxes out of the sediment occur in confined areas that are much smaller than the areas with fluxes into the sediment. In cohesive sediments, the mainly diffusive fluxes occur over the whole sediment surface in both directions, in and out of the sediment, with local hotspots, where directed bioturbative transport prevails. 

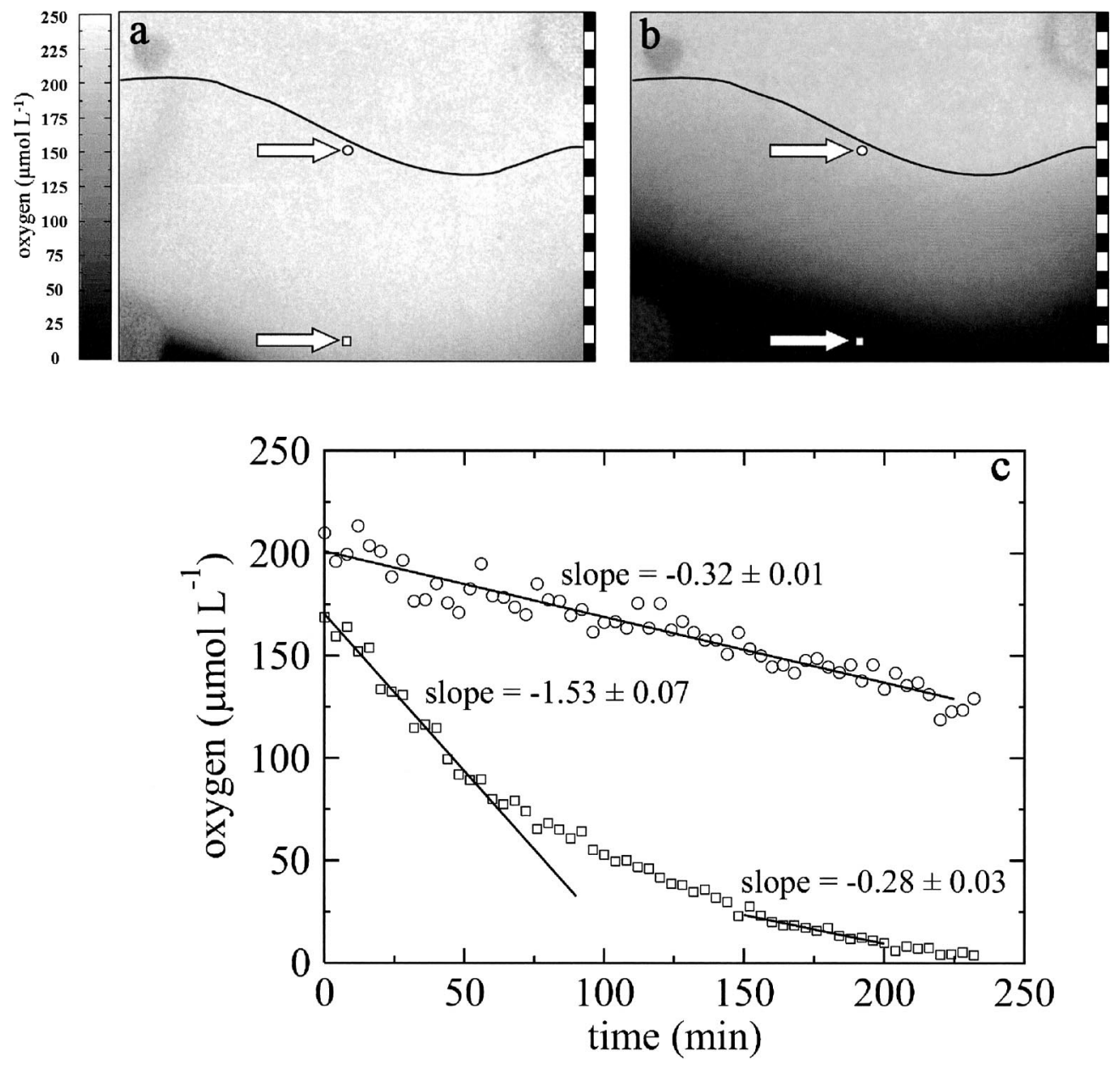

Fig. 7. Assessment of the oxygen consumption rates in the sediment. (a) Optode image of oxygen distribution directly after experiment 1. (b) Optode image of oxygen distribution 80 min after the experiment. The square and the circle (not to scale) indicate the areas of $3 \times 3$ pixels $(\sim 100 \times 100 \mu \mathrm{m})$ over which the oxygen consumption rates were calculated. (c) Fitting the changes of the $\mathrm{O}_{2}$ concentration over time: circles, $\mathrm{O}_{2}$ concentration close to the sediment corresponding to an OCR of $0.32 \pm 0.01 \mu \mathrm{mol} \mathrm{L}-1 \mathrm{~min}^{-1}$; squares, $\mathrm{O}_{2}$ concentration deeper in the sediment close to the initial oxic-anoxic boundary.

The advective pore water motion and the linked oxygen distribution also affect the microbiological system, which in turn affects the biochemical zonation. Prior to the experiments, the sediment in our study was kept under constant recirculating flow for 12 months; thus, the microbiological community had time to adjust to the new conditions. During the experiments, the oxic-anoxic boundary shifted, which implies that either the newly oxygenated zones became rapidly colonized by aerobes or that aerobic microorganisms were already present and became active. Because they are not the focus of this study, we have no information on these mechanisms. In later experiments, however, we can expect a microbial community that is tolerant against oxic and anoxic conditions and therefore adapted to the rapid changes in oxygen in the upper sediment layers.

Natural environments-The effect of wave action and bottom currents on interfacial pore water exchange was studied on an intertidal North Sea sandflat by Rutgers van der Loeff
(1981). An increased apparent diffusivity in the upper 1.5 $\mathrm{cm}$ of the sandy sediments was measured. Measurements of pore water oxygen profiles in the North Sea by Lohse et al. (1996) revealed that the effective oxygen diffusion coefficients in the surface layers of sandy sediments could be $>100$ times higher than the molecular diffusion coefficients, which was attributed to turbulent diffusion driven by nearbottom currents. Moreover, Webb and Theodor (1968) and Precht and Huettel (2004) observed that wave-driven advective pore water flow is a natural process occurring in nearshore environments. Because the processes studied here are caused by the interaction of boundary flows and topography, it could be argued that in spite of small wavelength and shallow water depth, the laboratory results are applicable to natural permeable sediments affected by waves.

Sandy sediments are abundant in the global continental shelf environment (Emery 1968; de Haas et al. 2002), and sands like our experimental sediment with a median grain size of $180 \mu \mathrm{m}$ are common on the shelf; for example, Cac- 


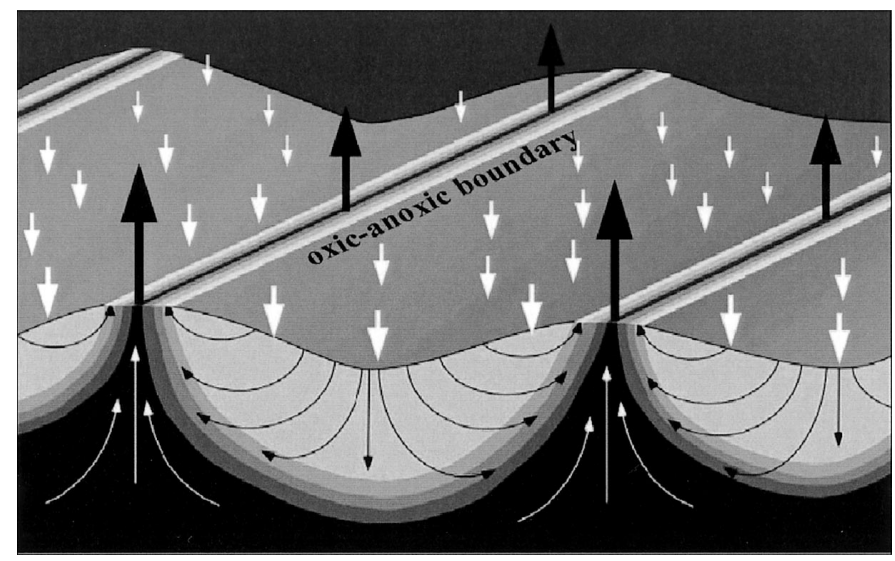

Fig. 8. Schematic drawing of the biogeochemical reaction zones underneath stationary ripples created by wave-induced advective pore water flow. In the center of the release areas, pore water from the deepest reaction zones emerges, whereas at the outer edges of these areas, pore water that resided for a shorter time in the sediment, and therefore has a different solute content, leaves the sediment. Black arrows indicate flow out of the sediment, white arrows flow into the sediment.

chione et al. (1999) and Ogston and Sternberg (1999) describe shelf sands with a grain size of $125-250 \mu \mathrm{m}$ and ripples of $9 \mathrm{~cm}$ wavelength at $60 \mathrm{~m}$ water depth.

Previous studies have shown that wave-induced boundary flows might reach the sediment surface in large areas of the global continental shelf down to $>100 \mathrm{~m}$ (Wiberg and Harris 1994; Harris and Wiberg 2001). The extent of the shelf areas affected by waves was numerically assessed by Harris and Coleman (1998): for example, in large areas of the southern North Sea, wave-induced flow exceeds the mobilization threshold for quartz sands of $100 \mu \mathrm{m}$ diameter $10-50 \%$ of the time.

However, the wave ripples that formed during our experiments were of the orbital type (Wiberg and Harris 1994), with wavelengths between 2.5 and $3 \mathrm{~cm}$. Under natural conditions, mainly anorbital ripples with comparable heights but longer wavelengths ( $\sim 9 \mathrm{~cm}$ for a sediment of our grain size) are formed. This suggests that, in nature, wave-driven pore water advection affects greater sediment depths than in our experiments, given that the permeability of the sediment is sufficiently high. As the pore water flow velocities decrease with depth, the oxic water entering the sediment in the ripple troughs will be deoxygenated by oxygen consumption because of the longer residence time in the sediment. Therefore, it is unlikely that the sediment depth affected by advective transport equals the actual sediment depth that is exposed to oxygen through advective flushing. Nevertheless, larger ripple spacing means that the sediment depth from which material can be released is increased. Thus, a storm event that produces or enhances bed ripples might affect sediment water exchange and penetration depth of advective pore flows much longer than its actual duration because of the persistence of the topography. After a storm, this "memory effect" might increase sedimentary biological and biogeochemical activity by the higher particle filtration and oxygen penetration associated with the "new" topography. a
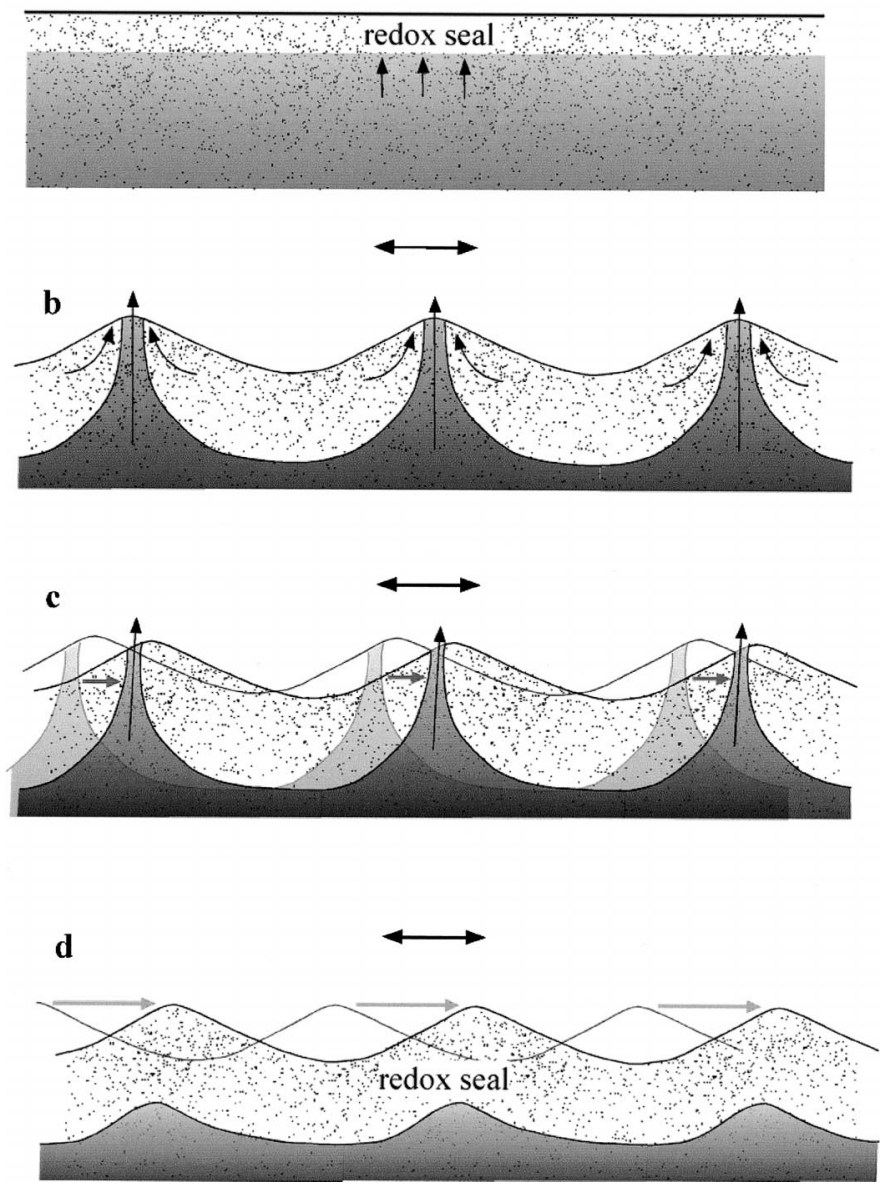

Fig. 9. Schematic diagram of (a) no sediment topography, oscillating flow; (b) stationary ripples; (c) ripples moving slower than pore water; (d) ripples moving faster than pore water. Grey indicates anoxic pore water. Arrows indicate water or pore water flow directions. See text for further details.

Effect of sediment topography-This study revealed four scenarios of advective interfacial exchange caused by waves dependent on the existence and mobility of sediment topography (Fig. 9).

(1) Sediment without significant topography: This scenario involves the development of a continuous oxidized sediment surface layer with a slightly increased oxygen penetration depth from small-scale advection, shear-driven Brinkman flow (Basu and Khalili 1999), and possibly wave pumping (Riedl et al. 1972). Additional solute release is caused by molecular diffusion and bioirrigation. The sediment is redox sealed, meaning that reduced substances that precipitate or are adsorbed under oxic conditions (e.g., $\mathrm{Fe}^{2+}$ ) cannot penetrate from deeper, anoxic sediment layers to the surface because they are trapped in the oxidized surface layer.

(2) Sediment surface with stationary ripples: This scenario has vertically alternating oxic and anoxic surface layers, with the oxygen penetration depth locally increased by 

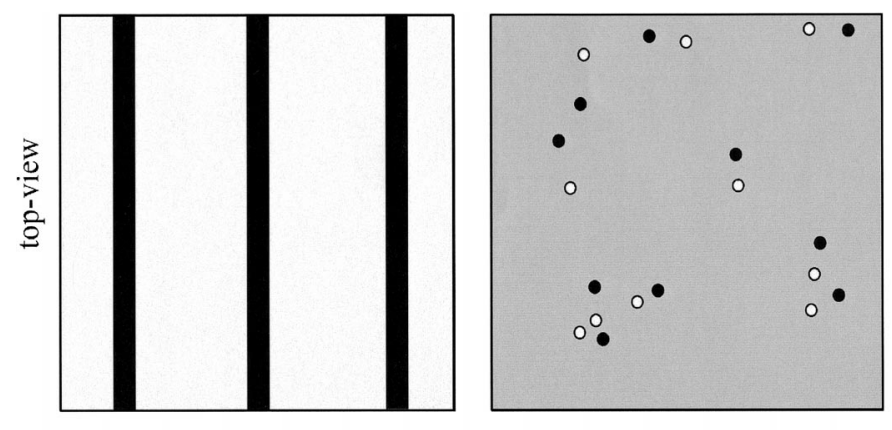

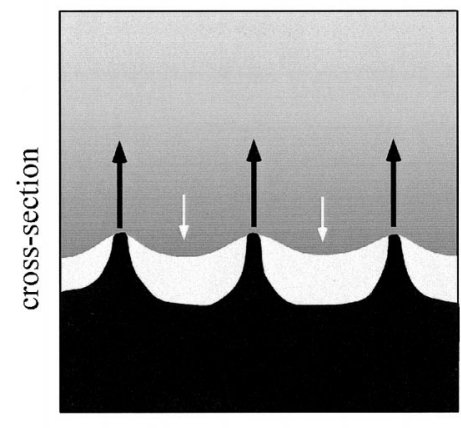

coarse-grained, "permeable" sediment

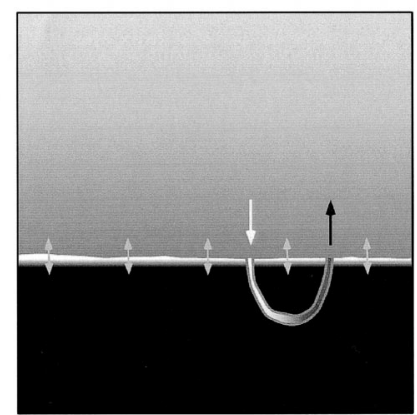

fine-grained, "impermeable" sediment
Fig. 10. Top views (upper panels) and cross-sections of a coarse-grained, rippled, permeable sediment (left) and a finegrained, impermeable bed (right). Black indicates solute flux from the sediment, white indicates solute flux into the sediment, and grey is simultaneous flux into and out of the bed at the same location in the impermeable bed. The flux in and out of a rippled, permeable bed is limited to distinct zones of in- and outflow, whereas the diffusive transport that prevails in fine-grained sediments occurs over the whole sediment surface area (with bioturbation producing local hotspots of transport).

nearly one order of magnitude. The flushed sediment volume compared to stagnant conditions increases more than threefold. Upwelling of pore water from deeper sediment layers creates anoxic channels to the surface, through which reduced substances can be released to the water column. A horizontal geochemical zonation develops at the ripple crests with the deepest, and likely strongest, reduced pore water emerging in the center of the ripple crest. With increasing distance from this central upwelling, the pore water released from the ripple originates from less and less deeper zones, thus containing lesser amounts of reduced substances. The vertical anoxic upwelling zones under the ripple crests might confine oxygen-dependent meiofauna to the sediment volume underneath the ripple troughs.

(3) Sediment surface with ripples moving slower than pore water: The flushed sediment volume relative to stagnant conditions increases more than threefold and is comparable with scenario 2. Mobile pore water upwelling zones, alternately exposing sediment volumes to oxic and anoxic conditions, enhance organic matter degradation in the upper sediment layer through associated redox oscillations (Aller 1994).

Anoxic upwellings passing through oxic zones could re- mobilize precipitated oxidized iron or manganese compounds and leach reduced $\mathrm{Mn}$ or Fe from the sediment. The cycling of $\mathrm{Fe}$ and $\mathrm{Mn}$ is believed to be closely linked to bioturbation because it constitutes the mechanism that transports oxidized precipitates into deeper, anoxic sediment layers, where they are remobilized (Aller 1990; Canfield et al. 1993). The mechanism we describe here opens a secondary pathway for the remobilization and cycling of oxidized metal precipitates.

Mobile vertical anoxic zones might cause migration of oxygen-dependent infauna and select for a bacterial community that is tolerant to oxygen and anoxic conditions. Sulfide oxidizers that depend on oxygen or that can store nitrate, like Beggiatoa (Jørgensen and Des Marais 1990) or Thioploca (Fossing et al. 1995; Huettel et al. 1996a), might profit from alternating pore water down- and upwelling. Likewise, nitrifiers and denitrifiers could profit from this alternating exposure.

(4) Sediment with ripples moving faster than pore water: In this case, the upwelling of pore water is too slow to follow the ripple migration. A continuous oxic layer can develop that creates a redox-sealed sediment with an undulating oxic-anoxic interface. The sediment volume flushed by oxygen-rich water reaches a maximum under these circumstances (increased more than sixfold to stagnant conditions). Intensive mixing of upwelling and downwelling pore water within the sediment might cause layers with increased precipitation of redox-sensitive substances (e.g., the common ferric iron coatings on surface layer sands).

Between scenarios 3 and 4, there is a gradual transition. In our experiments, when the ripples propagated at velocities of $<10 \mathrm{~cm} \mathrm{~h}^{-1}$, the oxygen-depleted zones under the ripple crests were fully developed with fully anoxic conditions in the centers (scenario 3). With ripple propagation velocities of $>20 \mathrm{~cm} \mathrm{~h}^{-1}$, the upwelling zone became detached from the ripple crests (scenario 4). With pore water velocities between 10 and $20 \mathrm{~cm} \mathrm{~h}^{-1}$, the oxygen-depleted zone trailed behind the ripple crest and showed only slight oxygen depletion. Therefore, ripple migration velocity defines not only how long a sediment volume is exposed to anoxic conditions but also the degree of anoxia and which spectrum of substances can be "leached" from the sediment because of the passage of an oxygen-depleted or oxic zone (applicable to $\mathrm{Fe}, \mathrm{Mn}, \mathrm{NO}_{3}, \mathrm{NH}_{4}, \mathrm{PO}_{4}$, and possibly to heavy metals like $\mathrm{Pb}, \mathrm{Cd}$, or $\mathrm{Hg}$ ).

Doucette et al. (2002) measured the migration rates of wave ripples $45 \mathrm{~m}$ offshore at shallow water depths with ripple wavelengths and sediment grain sizes comparable to those in our study. They observed averaged ripple migration rates of $55 \mathrm{~cm} \mathrm{~h}^{-1}$, which would mean that, at least in the highly mobile nearshore environment, scenario 4 of a redoxsealed sediment with completely oxic surface layer occurs. Migration rates of larger wave ripples (ripple wavelengths typically $10-100 \mathrm{~cm}$; sediment median grain size $=400 \mu \mathrm{m}$ ) were measured by Traykovski et al. (1999) at $11 \mathrm{~m}$ water depth, and it was found that these bedforms moved at velocities between 1 and $3 \mathrm{~cm} \mathrm{~h}^{-1}$. These values show that all 
the scenarios we described for the flume sediment can occur in natural environments.

We conclude that surface gravity waves can control oxygen transport and distribution in shallow permeable sediments. Because this influence is affected by the formation of sediment wave ripples and associated advective pore water flows, the regularity of the ripple topography is reflected in the oxygen distribution pattern in the upper sediment layer, with alternating zones of oxic and anoxic sediment. This establishes a fundamental difference between fine-grained, impermeable sediments and sandy permeable beds. Although in the fine-grained beds the diffusive sediment-water solute exchange takes place everywhere at the surface and simultaneously in both directions (into and out of the sediment via diffusion and associated counterdiffusion), influx and efflux is spatially well separated in permeable sand beds, with solute penetration in the ripple troughs and solute release from the ripple crests (Fig. 10). Thus, the fluxes into the sediment take place through a larger surface area than the fluxes out of the sediment. The separation of influx and efflux can generate a regular pattern of extremely different biogeochemical zones at the surface. The tight link between topography and pore water flow fields makes this distribution pattern highly dynamic, as ripples migrate or change their shape. Through the persistence of ripples after a storm event, this memory effect of the sea bed might control sediment metabolism a long time after such an event, through advective exchange caused by the interaction of boundary flows (e.g., tidal flows) and relict topography.

\section{References}

ALLER, R. C. 1982. The effects of macrobenthos on chemical properties of marine sediment and overlying water, p. 53-102. In P. L. McCall and M. J. S. Tevesz [eds.], Animal-sediment relations. Plenum Press.

. 1990. Bioturbation and manganese cycling in hemipelagic sediments. Phil. Trans. R. Soc. Lond. A 331: 51-68.

- 1994. Bioturbation and remineralization of sedimentary organic matter: Effects of redox oscillation. Chem. Geol. 114: 331-345.

Ballew, R. M., AND J. N. Demas. 1989. An error analysis of the rapid lifetime determination method for the evaluation of single exponential decays. Anal. Chem. 61: 30-33.

BAsU, A. J., AND A. KhaliLI. 1999. Computation of flow through a fluid-sediment interface in a benthic chamber. Phys. Fluids 11: $1395-1405$.

BERNER, R. A. 1980. Early diagenesis-a theoretical approach. Princeton Univ. Press.

BooiJ, K., W. Helder, AND B. SundBy. 1991. Rapid redistribution of oxygen in a sandy sediment induced by changes in the flow velocity of the overlying water. Neth. J. Sea Res. 28: 149-165.

CAcchione, D. A., P. L. Wiberg, J. LynCh, J. Irish, AND P. TrayKOVSKI. 1999. Estimates of suspended-sediment flux and bedform activity on the inner portion of the Eel continental shelf. Mar. Geol. 154: 83-97.

Canfield, D. E., B. Thamdrup, and J. W. Hansen. 1993. The anaerobic degradation of organic-matter in Danish coastal sediments-iron reduction, manganese reduction, and sulfate reduction. Geochim. Cosmochim. Acta 57: 3867-3883.

de HaAs, H., T. C. E. van Weering, And H. DE Stigter. 2002. Organic carbon in shelf seas: Sinks or sources, processes and products. Cont. Shelf Res. 22: 691-717.
DenNy, M. W. 1988. Biology and the mechanics of the wave-swept environment. Princeton Univ. Press.

Doucette, J. S., E. S. Harvey, AND M. R. Shortis. 2002. Stereovideo observation of nearshore bedforms on a low energy beach. Mar. Geol. 189: 289-305.

ElliotT, A. H., AND N. H. BRoOKS. 1997a. Transfer of nonsorbing solutes to a streambed with bed forms: Theory. Water Resour. Res. 33: 123-136.

- AND 1 1997b. Transfer of nonsorbing solutes to a streambed with bed forms: Laboratory experiments. Water Resour. Res. 33: 137-151.

EMERY, K. O. 1968. Relict sediments on continental shelves of the world. Am. Assoc. Pet. Geol. Bull. 52: 445-464.

Forster, S., M. Huettel, AND W. ZiEBIS. 1996. Impact of boundary layer flow velocity on oxygen utilisation in coastal sediments. Mar. Ecol. Prog. Ser. 143: 173-185.

Fossing, H., AND OTHERS. 1995. Concentration and transport of nitrate by the mat-forming sulfur bacterium Thioploca. Nature 374: 713-715.

Glud, R. N., N. B. Ramsing, J. K. Gundersen, and I. Klimant. 1996. Planar optrodes: A new tool for fine scale measurements of two-dimensional O-2 distribution in benthic communities. Mar. Ecol. Prog. Ser. 140: 217-226.

, C. M. Santegoeds, D. De Beer, O. Kohls, and N. B. RAMSING. 1998. Oxygen dynamics at the base of a biofilm studied with planar optodes. Aquat. Microb. Ecol. 14: 223233.

-, M. KuHL, O. KoHls, AND N. B. Ramsing. 1999. Heterogeneity of oxygen production and consumption in a photosynthetic microbial mat as studied by planar optodes. J. Phycol. 35: $270-279$.

- A. Tengberg, M. Kuhl, P. O. J. Hall, I. Klimant, And G. Holst. 2001. An in situ instrument for planar O-2 optode measurements at benthic interfaces. Limnol. Oceanogr. 46: 2073-2080.

HARRIS, C. K., AND P. L. WiBERG. 2001. A two-dimensional, timedependent model of suspended sediment transport and bed reworking for continental shelves. Comput. Geosci. 27: 675690.

Harris, P. T., AND R. Coleman. 1998. Estimating global shelf sediment mobility due to swell waves. Mar. Geol. 150: 171-177.

Holst, G., AND B. GRUnwald. 2001. Luminescence lifetime imaging with transparent oxygen optodes. Sens. Actuator B Chem. 74: 78-90.

, O. Kohls, I. Klimant, B. Konig, M. Kuhl, And T. RichTER. 1998. A modular luminescence lifetime imaging system for mapping oxygen distribution in biological samples. Sens. Actuator B Chem. 51: 163-170.

Huettel, M., AND A. Rusch. 2000. Transport and degradation of phytoplankton in permeable sediment. Limnol. Oceanogr. 45: 534-549.

— S. Forster, S. KLoser, AND H. Fossing. 1996a. Vertical migration in the sediment-dwelling sulfur bacteria Thioploca spp. in overcoming diffusion limitations. Appl. Environ. Microbiol. 62: 1863-1872.

- W. ZiEBIS, AND S. Forster. 1996b. Flow-induced uptake of particulate matter in permeable sediments. Limnol. Oceanogr. 41: 309-322.

\section{,,-- , AND G. I. LUTHER. 1998. Advective trans-} port affecting metal and nutrient distribution and interfacial fluxes in permeable sediments. Geochim. Cosmochim. Acta 62: 613-631.

—, AND I. T. Webster. 2001. Porewater flow in permeable sediments, p. 144-179. In B. P. Boudreau and B. B. Jørgensen [eds.], The benthic boundary layer. Oxford Univ. Press.

Jørgensen, B. B., AND D. J. Des Marais. 1990. The diffusive 
boundary layer of sediments: Oxygen microgradients over a microbial mat. Limnol. Oceanogr. 35: 1343-1355.

KaUtsky, H. 1939. Quenching of luminescence by oxygen. Trans. Faraday Soc. 35: 216-219.

Klimant, I., AND O. S. Wolfbeis. 1995. Oxygen-sensitive luminescent materials based on silicone-soluble ruthenium diimine complexes. Anal. Chem. 67: 3160-3166.

-, V. Meyer, AND M. KüHL. 1995. Fiber-optic oxygen microsensors, a new tool in aquatic biology. Limnol. Oceanogr. 40: $1159-1165$.

Klute, A., AND C. Dirksen. 1986. Hydraulic conductivity and diffusivity: Laboratory methods, p. 687-734. In A. Klute [ed.], Methods of soil analysis-part 1-physical and mineralogical methods. American Society of Agronomy.

KRöGEL, F. 1997. Einfluß von Viskosität und Dichte des Seewassers auf Transport und Ablagerung von Wattsedimenten (Langeooger Rückseitenwatt, südliche Nordsee). Ber. Fachbereich Geowiss. Univ. Bremen 102: 1-168.

Liebsch, G., I. Klimant, B. Frank, G. Holst, and O. S. WolfBEIS. 2000. Luminescence lifetime imaging of oxygen, $\mathrm{pH}$, and carbon dioxide distribution using optical sensors. Appl. Spectrosc. 54: 548-559.

Lohse, L., E. H. G. Epping, W. Helder, and W. VanraAphorst. 1996. Oxygen pore water profiles in continental shelf sediments of the North Sea-turbulent versus molecular diffusion. Mar. Ecol. Prog. Ser. 145: 63-75.

Ogston, A. S., And R. W. Sternberg. 1999. Sediment-transport events on the northern California continental shelf. Mar. Geol. 154: 69-82.

Papkovsky, D. B., J. Olah, I. V. Troyanovsky, N. A. Sadovsky, V. D. Rumyantseva, A. F. Mironov, A. I. Yaropolov, And A. P. SAvitsky. 1992. Phosphorescent polymer films for optical oxygen sensors. Biosens. Bioelectron. 7: 199-206.

Precht, E., AND M. Huettel. 2003. Advective pore water exchange driven by surface gravity waves and its ecological implications. Limnol. Oceanogr. 48: 1674-1684. $\longrightarrow$, AND 2004. Rapid wave-driven advective pore water exchange in a permeable coastal sediment. J. Sea Res. 51: 93-107.

Riedl, R. J., N. HuAng, AND R. Machan. 1972. The subtidal pump: A mechanism of interstitial water exchange by wave action. Mar. Biol. 13: 210-221.

RUTGERS VAN DER LOEFF, M. M. 1981. Wave effects on sediment water exchange in a submerged sand bed. Neth. J. Sea Res. 15: $100-112$.

Rutherford, J. C., J. D. Boyle, A. H. Elliott, T. V. J. HathERELL, AND T. W. CHIU. 1995. Modeling benthic oxygen-uptake by pumping. J. Environ. Eng. 121: 84-95.

SHuM, K. T. 1992. Wave-induced advective transport below a rippled water-sediment interface. J. Geophys. Res. 97: 789-808.

. 1993. The effects of wave-induced pore water circulation on the transport of reactive solutes below a rippled sediment bed. J. Geophys. Res. 98: 10,289-10,301.

Traykovski, P., A. E. Hay, J. D. Irish, and J. F. Lynch. 1999. Geometry, migration, and evolution of wave orbital ripples at LEO-15. J. Geophys. Res. 104: 1505-1524.

WeBB, J. E., AND J. THEODOR. 1968. Irrigation of submerged marine sands through wave action. Nature 220: 682-683. - AND —. 1972. Wave-induced circulation in submerged sands. J. Mar. Biol. Assoc. U.K. 52: 903-914.

WiberG, P. L., AND C. K. HARRIS. 1994. Ripple geometry in wavedominated environments. J. Geophys. Res. 99: 775-789.

Woods, R. J., S. Scypinski, L. J. C. Love, And H. A. Ashworth. 1984. Transient digitizer for the determination of microsecond luminescence lifetimes. Anal. Chem. 56: 1395-1400.

Ziebis, W., M. HuetTEL, AND S. Forster. 1996. Impact of biogenic sediment topography on oxygen fluxes in permeable seabeds. Mar. Ecol. Prog. Ser. 140: 227-237.

Received: 7 August 2003 Accepted: 20 November 2003 Amended: 18 December 2003 